Archived version from NCDOCKS Institutional Repository http://libres.uncg.edu/ir/asu/

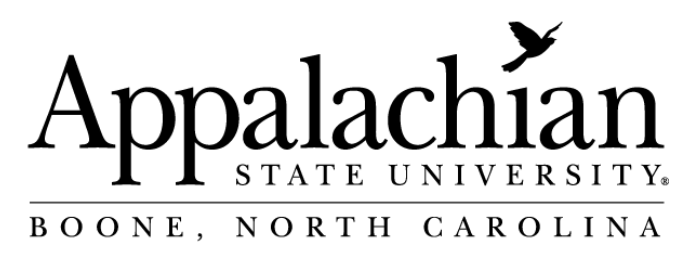

\title{
Different Commonalities: . Gender Mainstreaming and the Marginalization: of Difference in Economic Development
}

\section{By: Cynthia A. Wood}

\begin{abstract}
Gender mainstreaming in economic development has occurred in terms that contribute to the homogenization of women's experiences and to the exclusion of difference as legitimate terrain of analysis at institutionssuch as the World Bank. Feminist difficulties with the theory and politics of difference have been and willcontinue to be complicit with this problematic aspect of gender mainstreaming at such institutions. Since differences among women are at least as important as commonalities in defining needs and grounds for political action, the exclusion of difference from the discourse of development must be challenged directly in feminist theory and practice.
\end{abstract}

Wood, Cynthia. "Different Commonalities: Gender Mainstreaming and Marginalization of difference in Economic Development" Canadian Journal of Development Studies 26 special Issue (2005). [ISSN] 0225-5199 
Wood, Cynthia. "Different Commonalities: Gender Mainstreaming and the Marginalization of Difference in Economic Development" Canadian Journal of Development Studies 26 Special Issue (2005). (ISSN: 0225-5199) Permission to archive received sept. 21, 2010.

\section{Different Commonalities: Gender Mainstreaming and the Marginalization of Difference in Economic Development}

\section{Cynthia A. Wood}

ABSTRACT - Gender mainstreaming in economic development has occurred in terms that contribute to the homogenization of women's experiences and to the exclusion of difference as legitimate terrain of analysis at institutions such as the World Bank. Feminist difficulties with the theory and politics of difference have been and will continue to be complicit with this problematic aspect of gender mainstreaming at such institutions. Since differences among women are at least as important as commonalities in defining needs and grounds for political action, the exclusion of difference from the discourse of development must be challenged directly in feminist theory and practice.

RESUME - L'intégration de la dimension de genre dans le développement économique s'est produite dans des conditions qui contribuent à homogénéiser les expériences des femmes et à exclure la différence comme terrain d'analyse légitime dans les institutions comme la Bar:que mondiale. Les difficultés des féministes par rapport aux théories et aux politiques de la différence ont contribué, et continueront de contribuer, au problème de l'intégration de la dimension de genre dans ces institutions. Puisque les différences entre les femmes sont au moins aussi importantes que leurs traits communs pour définir les besoins et les raisons de l'action politique, il faut contester directement, dans la théorie et la pratique féministes, l'exclusion de la différence du discours sur le développement.

There is ... an intimate relationship between ways of thinking and ways of doing. In particular, the inclusions and exclusions that characterize different ways of thinking will help to determine what is considered worth thinking about and what is considered worth doing .... The world-views underpinning different analytical frameworks for analyzing gender and development bear critically, not only on how policy is formulated, designed, implemented and evaluated, but also on which issues are considered important and who are identified as the main actors in the development process (Kabeer 1994, 303).

\section{INTRODUCTION}

The how and why of gender mainstreaming are major topics of feminist analysis and frustration, especially in considering those institutions that continue to dominate economic governance of the "developing world," such as the World Bank and the IMF. The majority of this analysis is focused on the degree to which such mainstreaming has avoided gender transformative approaches to development and instead attempted to institutionalize instrumental approaches aimed at increasing efficiency. Most critics argue, for example, that the World Bank addresses gender only to the degree that the neoliberal economic paradigm remains unchallenged or is enabled, as exemplified 
in the long-overdue Bank report Engendering Development, the continued absence of gender analysis in macroeconomic policy-making (Bergeron 2004; Kardam 1991; O'Brien et al. 2000; Wood 2003), and the Bank's position that gender advocates must "make the business case for gender" (O'Brien et al. 2000, 48).

While the avoidance of transformative approaches is clearly an ongoing challenge for efforts to improve gender analysis and policy emerging from such institutions, there is another issue that has escaped attention in feminist analysis: how has the diversity of women's experiences been addressed (or not addressed) in the process of gender mainstreaming? I will argue in this paper that the institutionalization of gender as part of the business of development has occurred in terms that contribute to the homogenization of women's experience and to the avoidance of difference as a legitimate terrain of analysis. I will also argue, however, that ongoing feminist difficulties with the theory and politics of difference have been and will continue to be complicit with this problematic aspect of gender mainstreaming. If, as I believe, differences among women are at least as important as commonalities in defining needs and grounds for political action, the homogenizing tendencies of gender mainstreaming and the exclusion of difference from the discourse of development must be addressed directly in feminist evaluations of gender mainstreaming, a process I only begin with this paper.

To offer the first of many caveats, I understand that the institutionalization of gender mainstreaming I will be defining as problematic is simultaneously a mark of political success resulting from the hard work of gender advocates both outside and within development institutions (see Staudt 2002). It may be that women are made better off by gender being mainstreamed in this way, though I think this is an assumption that requires examination (see Batliwala and Dhanraj n.d.). However, I fear the homogenization of gender analysis that seems to accompany such mainstreaming, and I believe that far from undermining effective political action, as many feminists feel comfortable asserting, embracing attention to difference is essential to it.

We must seek out the implications of both avoiding and asserting difference in this context. What are the dangers of universal principles in gender mainstreaming? What does ignoring difference mean for "engendered" economic policy? Can attention to difference be institutionalized and, if so, what would this look like? Do the differing contexts of "first" and "third" worlds matter to this discussion?

\section{Homogenizing INSTITUTIONS}

Homogenization of women's experiences through mainstreaming, especially at large institutions, results in part because it is just easier if gender analysis is applied everywhere in the same way. In fact, that is part of the imperative of gender mainstreaming: to make it simple to understand so that people who do not specialize in gender can nevertheless learn it and apply it in their work; that is, to develop a "standard operating procedure" or "best practice" for gender. It is far easier to learn principles of content: "women are like $\mathrm{x}$," than principles of theory: "gender inequality can express itself in many ways, so you need to watch out for it and analyse it. Here are some examples, but they are only examples." And if specialists familiar with specific regions can't be around to ensure the proper application of theoretical principles of gender inequality, it may be that best practice dictates we train development practitioners, who are not always particularly interested in gender, in a few simple ideas that will prevent those well-known errors with the most damaging effects on women from happening yet again. In this context, addressing differences between women is a challenge for gender mainstreaming exactly because what it seeks to do is establish and enact universal principles.

It is also the case, however, that the theory of gender mainstreaming, at least as applied by large development institutions, has become one recognizable thing, with established methods, approaches, 
and objects of study. A very few people, organizations, and documents, such as Caroline Moser's Gender Planning and Development (1993) ${ }^{1}$ and The Oxfam Gender Training Manual (Williams 1994), can be pointed to as constituting the canon of practical and credible application of feminist approaches to development at such institutions. I will discuss specifics of gender-analysis frameworks below, but here the point I want to make is that approaches to gender mainstreaming are both homogenized and homogenizing of women's experience at some level simply because they have been so broadly institutionalized. It is certainly the case also that the need to satisfy the institutions themselves on practical and ideological grounds contributes to this homogenization of the theory of gender mainstreaming. The large development agencies involved in economic governance of the third world ${ }^{2}$ - are committed to efficiency and technical approaches to development deriving from "expert" knowledge. The messiness of paying special attention to differences among women for purposes of policy design does not fit well into this rubric.

It may be that there is no help for this particular problem. Since we certainly want the institutionalization of gender analysis in large development agencies, we may be stuck with the tendency to homogenize; institutionalization itself may require or inevitably result in such homogenization. And again, women may benefit from gender mainstreaming even when it homogenizes in this way. But without discussion of what is lost by marginalizing difference, this process cannot really be evaluated.

\section{HoMOgENIZING EcoNomics}

In considering gender mainstreaming and the lack of attention to difference in the context of economic governance, it is important to recognize the powerful impetus in neoliberal economics to assume and assert universal economic principles applicable to all people and economies. Because neoliberal economics dominates institutions such as the World Bank and the IMF, it is fighting against the tide at these institutions to push for analysis of any differences between people. Indeed, it is the theoretical centrality of this assumption in neoliberal economics that has made it difficult to mainstream attention to women at all, as demonstrated by the continuing struggle to have the Bank acknowledge the gendered effects of structural adjustment policies (Wood 2003). ${ }^{3}$

For my purposes, there are two aspects of the assumption of universal economic principles that are most relevant here. The first is that human nature is defined in terms of "economic man," a creature who is rational, self-interested, has insatiable wants, and enacts his agency through choice. There is a wealth of feminist criticism of this definition based on its emergence from male bias (Ferber and Nelson 1993; Barker and Kuiper 2003). A few critics have also addressed its ethnocentric or postcolonial character, with particular reference to "third world women" (e.g., Charusheela 2003). Second and related is the neoliberal argument that treating developing economies as a "special case" is a mistake and a fatal flaw of the old development economics. Universal economic principles of micro-

1. Note that Moser's book was published while she worked at the World Bank.

2. The hierarchy and homogeneity implied by the terms "first" and "third" worlds makes their use highly problematic, especially in the context of a paper critiquing the marginalization of difference. Nevertheless, I use them, because the opposition between "third" and "first" world experiences shapes development thinking so completely that my analysis of gender mainstreaming requires a highlighting of this opposition. I use the lower case in preference to the more common upper case to avoid transforming these terms into proper names that even further homogenize the diverse experiences of people in the South.

3. This tendency is confirmed in the literature on the economics of development. Many if not most economists addressing issues of development have learned enough from the rise of gender and development as a field to accept gender as a legitimate and relevant category of analysis for promoting development (albeit in instrumental terms acceptable to the neoliberal paradigm). However, this belief is far from institutionalized in the theory. Some central texts say nothing at all about women (see Meier and Stiglitz 2001). Others give substantial attention to gender analysis (Meier and Rauch 2000, 263-88; Todaro and Smith 2003). 
and macroeconomics, this argument asserts, apply in the third world in exactly the same way they do in the first, and in each individual country as well. In other words, it is similarities between people and economies that define the arena for economic analysis from the neoliberal perspective. This suggests that any gender mainstreaming that occurs at institutions dominated by this perspective will be particularly liable to resist the view that differences between women are an important aspect of economic analysis (see Peet and Hartwick 1999, 49).

Neoliberal economics may in fact be predicated on the exclusion of questions of difference. Suzanne Bergeron points out that recent developments in the economics of "social exclusion" have created an opening for discussions of gender acceptable to the neoliberal model, but that the distinction between "economic" and "social and cultural" issues remains unchallenged in this approach (Bergeron 2004, 9-13). This distinction is an important one for my argument because neoliberal economists would categorize differences between women as social and cultural issues outside the realm of (universal) economic analysis. If economics, as understood by mainstream economists, is constituted by its separation from the social and the cultural, difference understood as something more than the abstract disembodied "gender" cannot become part of neoliberal economic analysis. ${ }^{4}$

\section{The Case of Gender Training}

One of the most important implications of gender mainstreaming is that people who are not experts (or even interested) in gender issues must be sufficiently familiarized with basic concerns that they can "do" gender, whether in grassroots organizations or large development institutions. Gender training (and the conceptual frameworks underlying such training) is thus a major conduit for defining what is important and how difference will be treated in gender analysis. While such training often suggests that gender must be seen in the context of race, class, ethnicity, and other sources of inequality, with few exceptions it does so in such a way as to marginalize difference. At the practical level of gender training, then, feminist development practitioners contribute to the tendency to homogenize women's experience.

This happens because the purpose of gender training is to establish conceptual tools that can be used and replicated anywhere. Ruth Pearson emphasizes my concern here: "Gender planning frameworks are seductively universal, presented as providing universally applicable tools. Experience has shown, however, that they are not universal" (quoted in March et al. 1999, 14). This tendency to universalize reasserts itself throughout discussions of gender analysis in the context of development, in part because the method requires abstracting gender as a category of analysis for purposes of instruction, an abstraction that certainly does not require and often resists attention to differences between women. To demonstrate this I will look at discussions of difference as they play out in Oxfam's manual A Guide to Gender-Analysis Frameworks, which attempts to summarize and evaluate the best-known or most institutionalized of the conceptual approaches underlying gender training (March et al. 1999). ${ }^{5}$

The definitions important to discussing gender are laid out in the Guide with substantial attention to difference, as is true of most gender and development (GAD) analysis:

4. The degree to which feminist economics escapes this problem is open to debate.

5. The Guide presents overviews and brief evaluations of the Harvard Analytical Framework, Moser Framework, Gender Analysis Matrix (GAM), Capacities and Vulnerabilities Analysis Framework, Women's Empowerment (Longwe) Framework, and the Social Relations Approach. 
The experience of being male or female differs dramatically from culture to culture ... Gender relations vary according to time and place, and between different groups of people. They also vary according to other social relations such as class, race, ethnicity, disability, and so on.... The gender division of labor varies from one society and culture to another, and within each culture, it also changes with external circumstances and over time (18).

The reader is also cautioned that "[ $t$ ]hose using gender frameworks must not ignore cultural differences" (14). Comparisons and evaluations of the different gender-analysis frameworks are made in part on the basis of whether or not they "go beyond" gender in their analyses of social relations (23).

But the terms by which these concerns are integrated into the gender-analysis frameworks presented, as well as the Oxfam evaluations of these frameworks, marginalize difference in general and in the particular locales in which gender training is enacted. First, consideration of local concerns and differences is established as necessary only for the successful transmission of an already defined framework: "the trainer faces the considerable challenge of finding examples and case studies which reflect the realities of the individual location, in order to make the framework pertinent and effective" (14). This is important, according to the Guide, in order to avoid trainees or project beneficiaries feeling "confused and offended by what they may perceive as insensitive attacks against their culture or personal life" (14). The framework itself is not subject to change in response to local conditions as presented here; it is only the mechanism of transmission that must be altered to make it more palatable to the locals. And the possibility that what happens in gender training may actually be insensitive attacks on culture or personal life is not allowed, only confused misperception on the part of the trainees. "All explanations and definitions must be translated and adapted to each local context" (17), but the analytic core brought to the training remains intact.

Again, I want to emphasize that I respect much of the good and difficult work that gender trainers do. What I am arguing for here is an understanding of the limitations and blind spots in gender mainstreaming. The impossibility of local conditions and differences actually shaping the theoretical framework of gender analysis means that it will always be asserting some universals, and the fact that these frameworks have emerged for the most part in the North should give us pause. As Srilatha Batliwala and Deepa Dhanraj suggest:

This also raises a question about whether the training process has not created a net loss in terms of alternative narratives and analytical frameworks that allow women and men to examine the experience of gender in a vernacular way, without succumbing to the dominant discourse. Has gender training, even by feminists, in fact led to the creation of a peculiar dominant feminist discourse? And to the loss of a very rich vocabulary, profound metaphors, even their very culture? (n.d., 8).

Perhaps existing GAD frameworks can be "adapted" enough to local conditions to actually represent not only local realities but also local understandings of desirable change. But perhaps not.

A more obvious way in which difference is elided in gender-analysis frameworks is that, with the exception of Naila Kabeer's "Social Relations Approach," it is not necessary for differences between women to be addressed at all, though several allow the possibility of including such concerns. In addition, when it is possible for differences to be included as part of the framework, they generally must be specified in advance; that is, it must be decided to include class, race, age, or some other specific difference. This means, first, that differences between women are treated as dispensable even when they are discussed, and in some cases they are dealt with as a problem for understanding 
gender. Secondly, it is assumed that important differences do not need to be defined "on the ground," since they are already known (class, race, ethnicity, age, etc.). Certainly many important differences between women will fall along these accepted and recognized lines of inequality. But to establish a list of recognized differences does not lead to an analytic frame that is attentive to difference in general, however well it may address the differences specified. Certain differences, perhaps the most contentious (either to the trainers or the trainees), are less likely to be put on this list even when they are common to many cultures - for example, alternative sexualities. Others may be so specific to the local community that they would not appear for that reason.

In the context of universalizing gender-analysis frameworks, the use of case studies and local examples during gender training does not contribute to establishing or defining the importance of difference, or even to clarifying locally important differences between women. I have argued elsewhere that the most common use of case studies is to demonstrate that women are the same; they are presented as facing similar situations in different places and behaving in more or less the same way when confronted by those situations, as in the comments by a gender training participant quoted in The Oxfam Gender Training Manual: "At this training we have learnt that women are all the same: they fight for survival, and do not wait for a man to bring food" (Williams 1994, xi). Case studies are thus used to confirm already defined universals; situations unique to certain locales or women will never be presented as case studies in gender training because this would confuse the issue (Wood 2002).

The Oxfam Guide points out that "[ $t$ ] he selection of factors in any particular framework reflects a set of values and assumptions on the part of the author(s) of the framework" (22). That difference is so consistently excluded or marginalized suggests that it is assumed to be irrelevant, not useful, or obstructive to understanding gender as represented in gender-analysis frameworks and to the gender transformative work assumed to emerge from appropriate political action. This position is implicit, but revealing of a deep conflict over difference in feminist theory itself.

\section{Homogenizing Feminist Theory}

Conflict over difference, most explicitly addressed in transnational feminist theory, underlies one aspect of the homogenizing impetus of gender mainstreaming in the context of development, and as such needs to be explicated. ${ }^{6}$ While it is true that the "global (or white liberal) feminist" position that women are oppressed everywhere in the same way is generally challenged by feminists today, there is also widespread discomfort with questions of difference raised in transnational feminist theory, particularly in postmodern varieties of that theory (Mendoza 2002, 300). Indeed, it has become a commonplace sentiment among development practitioners working on gender that postmodernism, by focusing so much on difference, makes political action impossible (see Pearson and Jackson 1998, 5-6). From this perspective, "too much" attention to difference is divisive because solidarity requires universals.

This tension, interestingly, is demonstrated very well in Chandra Mohanty's latest book Feminism Without Borders. In 1986, Mohanty argued in her essay "Under Western Eyes" that the global feminist assumption of universal patriarchy was ethnocentric, in general as well as in specific applications to development:

6. See Mendoza (2002) for an excellent analysis of the treatment of difference and the potential for global solidarity among women in transnational feminist theory. 
Concepts such as the sexual division of labor can be useful only if they are generated through local contextual analysis ... If such concepts are assumed to be universally applicable, the resultant homogenization of class, race, religion and daily material practice of women in the Third World can create a false sense of the commonality of oppressions, interests, and struggles between and among women globally. Beyond sisterhood there are still racism, colonialism, and imperialism (Mohanty 2003, 36).

In particular, she argued, much feminist analysis of development is based upon or contributes to the production of an "average third world woman," whose essential character of passive victimhood justified Northern women's intervention as saviours (40). While this version of global feminism assumes an essential difference between first and third world women, on either side of that divide there are no distinctions of class, race, ethnicity, or anything else (Mendoza 2002, 301). As Breny Mendoza points out, Mohanty's 1986 argument suggested that development thereby "becomes the substance of global feminist solidarity" as "gender planning conceived, directed (and even funded) by First World women" (and their middle-class Third World counterparts) is enacted in the poor countries such that "Third World women learn to develop the capabilities they are missing to lead less oppressive and exploited lives" (Mendoza 2002, 301). The necessary solution to this problematic feminist approach to development, according to Mohanty, was attention to difference. Concepts commonly used in feminist development analysis, such as "reproduction, the sexual division of labor, the family, marriage, household, patriarchy, and so on," should be generated and applied only in specific local and historical contexts (34). Without this fundamental shift in feminist analysis, feminist political practices are distorted in such a way as to "limit the possibility of coalition among (usually white) Western feminists, working class feminists, and feminists of color around the world" (18).

In her more recent writing, Mohanty qualifies this analysis. In the essay "'Under Western Eyes' Revisited," a chapter in Feminism Without Borders (2003), she critiques "problematic" anti-essentialist feminist readings of her work, and while she stops short of recanting her original argument, she is now uncomfortable, she says, with its emphasis on difference:

What is interesting for me is to see how and why "difference" has been embraced over "commonality," and I realize that my writing leaves open this possibility. In 1986 I wrote mainly to challenge the false universality of Eurocentric discourses and was perhaps not sufficiently critical of the valorization of difference over commonality in postmodern discourse. Now I find myself wanting to reemphasize the connections between local and universal. In 1986 my priority was on difference, but now I want to recapture and reiterate its fuller meaning, which was always there, and that is its connection to the universal. ... The challenge is to see how differences allow us to ... theorize universal concerns more fully (226).

Indeed, it is a challenge, and one I think she fails to meet. Leaving aside what I believe is her own misreading of post-structuralist feminism, the slippage between commonalities and universals is a serious one, and this confusion is the root of the contradictions endemic to her essay. Universals exist outside of human agency in the world of ideas, as when she uses the term "universal justice" (231). ${ }^{7}$

7. The desire for universals leads her to statements that clearly violate her own demand for historical specificity to avoid homogenizing and essentializing characterizations of third world women, as when she states, "Women of the two-thirds world have always organized against the devastations of globalized capital, just as they have always historically organized anticolonial and antiracist movements. In this sense they have always spoken for humanity as a whole" (237). I have argued elsewhere that essentializing third world women as powerful heroines serves much the same function in feminist analysis of development as Mohanty argued against in "Under Western Eyes" (see Wood 2001). 
Commonalities are rooted in material conditions that change over time in response to human action. The former leaves no room for difference. The latter does, and in a way that enables political action. In Feminism Without Borders Mohanty herself argues this point in the discussion on solidarity, which she sees as emerging from struggle rather than universal oppression.

I define solidarity in terms of mutuality, accountability, and the recognition of common interests as the basis for relationships among diverse communities. Rather than assuming an enforced commonality of oppression, the practice of solidarity foregrounds communities of people who have chosen to work and fight together. Diversity and difference are central values here - to be acknowledged and respected, not erased in the building of alliances $(2003,7)$.

The conflicts and contradictions in Mohanty's work illuminate a central tension in contemporary feminist thought about difference that inevitably appears also in gender analysis of development and social change. On the one hand, acknowledging difference is seen as important, indeed indispensable, to gender work in the third world. On the other, it is seen as divisive and an impediment to political action. Underlying this latter belief is the idea that solidarity is an unchanging state achieved without human thought or action, a position that justifies the work feminists do in the field, however implemented. We (white Western and/or middle-class women) are naturally in solidarity with poor women everywhere in the third world. What this means in practice is that as long as a nod is made "acknowledging" that there are differences between women, the failure to really incorporate difference as central to the theory and practice of gender mainstreaming won't be a topic of analysis even among feminists, either because it isn't seen as a problem or because ignoring difference is justified in terms of avoiding divisiveness.

That this tension plays out in gender analysis of development is clear in Oxfam's Guide to Gender-Analysis Frameworks. Gender trainers' complaints about the Social Relations Approach have to do with its attention to difference:

Gender may become subsumed in a complex examination of cross-cutting inequalities, posing an obstacle for political action ... women can get subsumed in many individual categories of, say, class or sector. Where this is the case, gender issues become fragmented within other issues of class, ethnicity, religion, and so on (118).

This is especially true because attention to difference requires a detailed understanding of local issues. "Complexity means very detailed knowledge of context is needed. The [Social Relations Approach] framework is difficult to use fully in situations where there is not very much information available" (118). Indeed. But these comments (and the homogenizing practices they imply) could not be made in the context of approaches to development that value difference.

\section{Conclusion}

I have argued in this paper that attention to difference in gender mainstreaming at institutions dominating economic governance is marginalized or excluded through several means: institutional resistance, neoliberal economic theory, most gender-analysis frameworks, and tensions in feminist thinking on the issue. Individually, any of these would make it less likely for differences between women to be addressed in gender mainstreaming at places such as the World Bank. 
Combined, they make it virtually certain that the "universal" will rule; not only will the Bank itself resist addressing difference, but it will not be asked to do so by feminists creating or implementing gender-analysis frameworks.

This matters because it means that even "successful" gender mainstreaming at institutions of economic governance will contribute to the implementation of policy based on homogenized and homogenizing visions of women in the South. Development has been critiqued for assuming that becoming just like the North is a desirable goal. Gender mainstreaming that does not take difference seriously, and thereby produces a "one-size fits all" approach, will similarly equate gender equality with what we strive to achieve in the North; that is, "integration into capitalist markets, the welfare state, literacy, and skill-based empowerment as the solution for women's oppression" (Bergeron 2004,13 ). Batliwala and Dhanraj argue for a more serious look at biases in the conceptual apparatus underlying feminist development practice:

It is time to look squarely at not only the provenance of certain feminist concepts "empowerment" or "space" or "identity," but also at the western/elite/modernist/liberaldemocratic nature of our constructs of liberation and equality, which privilege the individual and her rights over that of the community (n.d., 6).

Mainstreaming on these terms is no less a colonizing activity for the good intentions of its practitioners.

What this means for the feminist practice of development must be debated broadly, but there are several immediate implications. First, the concept of gender mainstreaming, to the degree that this entails the assertion and imposition of universal concepts, must be discarded in favour of forms of gender analysis and activism that take difference as a central organizing principle. At the practical level, this means that a profound understanding of local contexts is absolutely vital, and that no intervention in any community would take place where "little information is available" (March et al. 1999, 118); in fact, the impetus for gender activism cannot be imposed from outside, but must emerge from local needs and desires. This approach must become standard practice and acceptance of many feminisms the norm. Further defining what good gender training, analysis, or organizing will look like on the ground should be done very carefully, if at all, since all must emerge from local knowledge and struggle.

We should all become more careful in our usage of universalized feminist concepts such as "reproduction, the sexual division of labor, the family, marriage, household, patriarchy" (Mohanty 2003, 34), but also think deeply about larger concepts such as liberation, equality, justice, even gender. This does not mean that there cannot be conversation about these concepts across lines of geography, communities, class, caste, gender, race, sexualities, and so on. In fact, there must be not only conversation but practices of solidarity in Mohanty's sense: solidarity based on mutuality, accountability, and the building of relationships and activisms based on common interests rather than on assertions of universal oppression (7).

More broadly, this analysis suggests that far from undermining it, attention to difference is necessary to political action, and that practices of successful organizing for social change demonstrates this on a daily basis. Not looking at the differences between women does not make those differences go away; it just means they are not being dealt with, which limits the possibility of successful alliance. This possibility should not be romanticized, because it is only ever a possibility. If commonalities between women are rooted in material conditions, they establish the potential for both conflict and solidarity. The conflicts between women may be such that joint political action is impossible, as for 
example when rich women benefit from the exploitation of poor women. Asking poor women to "set aside" their concerns in the interest of universal womanhood is not politically sustainable in this case, and reveals the way such universalizing is a disguise for the implementation of the interests of the powerful.

Other conflicts between women are such that alliance on the basis of common interest is both important and possible. In that case, ignoring differences between women is fatal to political action because these differences need to be addressed. It is the asser tion of universality that is divisive; coalitions built without attention to difference are illusory and will fragment. It is equally vital for effective political action that commonalities be found and emphasized. But these commonalities have to be looked for and negotiated; thinking you know what they are in advance (because they are "universal") means that some will be asserted when they are not there and others will not be noticed because they don't "fit."

This view of politics is not comfortable for many feminists. It asserts that there are women who have no common interests or have such conflicts that uniting over "women's issues" is impossible. It means that politics is unstable, in the sense of never being able to stop the process of building coalitions and addressing difference. But this is true because material conditions change, not because post-structuralist feminism made it so.

It may be that the emphasis on difference is most important in situations where powerful and less powerful are working together. Ignoring difference is tempting in such situations; addressing it is uncomfortable for the powerful because it calls attention to their privilege, and it may be dangerous for less powerful people for the same reason. People working at the grassroots may be less inclined to ignore differences simply because of the nature of their work, or the differences they ignore may be unimportant.

If this is true, gender training by generic consultants from (or tied to) Northern multilateral institutions is more likely to work from damaging and colonizing universals than locally rooted gender training emerging from the grassroots that seek to build coalition on the basis of commonality. Gender training based on "expert" consultants brought in from the outside to teach therefore will not and should not survive new feminist approaches to development practice that give due attention to difference, at least not as currently implemented (see also Batliwala and Dhanraj n.d., 4-5).

We should not of course romanticize "the grassroots," either, because there are real differences between poor women as well, some of which may make coalition impossible or very difficult. And to the degree that women working at the grassroots inherit gender-analysis frameworks that marginalize difference, there is a limit to how far they can adapt these tools. Frameworks that begin with difference and build it into the fabric of analysis must be used instead. As I have argued, this approach is not likely to emerge in the current process of gender mainstreaming, particularly at economic institutions such as the World Bank. A new commitment to exploring and implementing the implications of attention to difference among feminist academics and development practitioners is necessary for this to change.

\section{REPERENCES}

Barker, D. and E. Kuiper (eds.) (2003) Toward a Feminist Philosophy of Economics, New York: Routledge.

Batliwala, S. and D. Dhanraj (n.d.) "Where Gender Meets Patriarchy, Fundamentalism and Neo-liberal Economics - A Report on Gender Myths and Feminist Fables from the Feminist Frontline," unpublished essay. 
Bergeron, S. (2004) "Bringing Gender In: Acts of Translation and Gender Mainstreaming at the World Bank," International Studies Association Convention, Le Centre Sheraton Hotel, Montreal, 19 March.

Charusheela, S. (2003) "Women's Choices and the Ethnocentrism/Relativism Debate," in S. Cullenberg et al. (eds.) Postmodernism, Economics and Knowledge, New York: Routledge.

Ferber, M.A. and J.A. Nelson (eds.) (1993) Beyond Economic Man, Chicago: University of Chicago Press.

Kabeer, N. (1994) Reversed Realities: Gender Hierarchies in Development Thought, New York: Verso.

Kardam, N. (1991) Bringing Women In: Women's Issues in International Development Programs, Boulder, CO: Lynne Rienner Publishers.

March, C. et al. (1999) A Guide to Gender-Analysis Frameworks, Oxford: Oxfam GB.

Meier, G.M. and J.E. Rauch (eds.) (2000) Leading Issues in Economic Development, New York: Oxford University Press.

Meier, G.M. and J.E. Stiglitz (eds.) (2001) Frontiers of Development Economics, New York: Oxford University Press.

Mendoza, B. (2002) "Transnational Feminisms in Question," Feminist Theory 3:3, 295-314.

Mohanty, C.T. (2003) Feminism Without Borders: Decolonizing Theory, Practicing Solidarity, Durham, NC: Duke University Press.

Moser, C. (1993) Gender Planning and Development: Theory, Practice and Training, New York: Routledge.

O'Brien, R. et al. (2000) Contesting Global Governance: Multilateral Economic Institutions and Global Social Movements, Cambridge: Cambridge University Press.

Pearson, R. and C. Jackson (1998) "Introduction: Interrogating Development," in C. Jackson and R. Pearson (eds.) Feminist Visions of Development, New York: Routledge.

Peet, R. and E. Hartwick (1999) Theories of Development, New York: The Guilford Press.

Staudt, K. (2002) "Dismantling the Master's House with the Master's Tools? Gender Work with Powerful Bureaucracies," in K. Saunders (ed.) Feminist Post-Development Thought, New York: Zed Books.

Todaro, M.P. and S.C. Smith (2003) Economic Development, New York: Addison-Wesley.

Williams, S. (1994) The Oxfam Gender Training Manual, Oxford: Oxfam UK and Ireland.

Wood, C.A. (2003) "Adjustment with a Woman's Face: Gender and Macroeconomic Policy at the World Bank," in S. Eckstein and T. Wickam-Crowley (eds.) Struggles for Social Rights in Latin America, New York: Routledge.

(2002) “Transforming 'Them' into 'Us': Some Dangers in Teaching Women and Development," in M.M. Lay, J. Monk, and D. Rosenfelt (eds.) Encompassing Gender: Crossing Disciplinary and Geographic Borders, New York: Feminist Press. 